From the Department of Child Health, Midical School, University of Indomesia, Jakarta.

\title{
Uses and Limitations of Gammaglobulin Therapy (Literature Review).
}

by

\author{
$S U M A R M O$
}

In the last 20 years gammaglobulin products have been used more and more in clinical medicine for both the prevention and treatment of infectious diseases. With the development of routine laboratory methods for the assessment of cellular and humoral immune competence, more patients with severe immunological deficiencies will be recognised, as will those with all shades of deficiency between complete absence of a functional immune system and the normal state (Simons, 1971). A major objective in the management of patients with hypo- or agammaglobulinaemia and other antibody deficiency states is to reduce their abnormality in susceptibility to infection, A survey carried out at the Hospital for Sick Children, London, revealed, that severe deficiency of cellular and humoral immunity was responsible for two per cent of all deaths (Berry, 1968). Clinical application of the advances made in basic immunological research is not restricted merely to the recognition and diagnosis of patients with immunological deficiency diseases, but also in rational immunological therapy.

This paper discusses the enormous advances in gammaglobulin therapy, its uses and limitations.

\section{Replacement of immunoglobulins}

One aspect of gammagilobulin therapy is the replacement of 'ihe deficient end products in those individuals in whom there is impaired function of immunoglobulin producing lymphoid tissues. Immunoglobulin replacement will contimue until means become available for overcoming the central cellular defect. The second aspect is the inhibitions of immune responses by immunoglobulin therapy.

* Participant of the 5th W.H.O. Immunology Training Course, Faculty of Medicine, University of Singapore, 6 May to 19 July, 1974.

Director: Dr. M.J. Simons.

Received 25th August. 1974. 
The clinical application of the gammaglobulin products for the prophylaxis and treatment of disease was regulated according to empiric experivence. Several authors with a large experience in gammaglobulin therapy have come to the conclusion that a definite, critical examination of the prophylactic and therapeutic actions of gammaglobulin preparations is not yet possible (Barandun, 1964).

Certainly in normal, the use of gammaglobulins to prevent viral infections may be valuable, but more interesting today are viral infections which cannot be managed by immunization procedures. In agammaglobulinaemic patients gammaglobulin is so far the most important prophylactic therapeutic agent to prevent repeated bacteriall infections.

The dose necessary for the prevention of several viral diseases is quite low (Rosen and Janeway, 1968), it increases, however, as the incubation period advances. After onset of the disease and particularly in cases of serious or prolonged infection, high doses of gammaglobulin are necessary to support the body efficaciously in its resistance to the pathogen. As a preventive measure, gammaglobulin is given at regular intervals in doses calculated to provide IgG levels of $200 \mathrm{mg}$ per $100 \mathrm{ml}$ i.e. levels suggested as being necessary for protection (Soothill, 1962), To achieve and maintain this serum IgG concentration, it is necessary to ad- minister large volumes at frequent intervals. The intramuscular injections are painful, and the effective dose achieved is less than that administered due to local tissue proteolysis of some of the gammaglobulins. Gammaglobulin cannot be injected intravenously, even in small quantities. Even if the product is diluted and all precautionary measures are taken, a large percentage of patients react in a range from subjective feelings of anxiety and oppression, pain in the back, to more severe reactions of fever, respiratory distress and circullatory collapse may even occur in rare casses. As all of us know, gammaglobulin and in particular aggregated gammaglobulin, is capable of binding and activating complement. Histamine and simillar substances are thus released which cause the side effects described.

Recent advances in immunoglobulin chemistry have enabled the preparation of specific immunoglobulin solutions, some of which may be administered intravenously. The investigation of these preparations gave the following theoretical results (Barandun et al., 1962; Barandun, 1964): The intolerance toward native gammaglobulins is dependent upon an endogenous individual factor. This is demonstrated by the fact that only certain individuals react to the intravenous application of gammaglobulin. The intolerance toward native gammaglobulins is also dependent upon an exogenous general fac- 
TABLE 1: Comparison of 7 preparations of intravenous gammaglobulin labeled with $I^{131}$

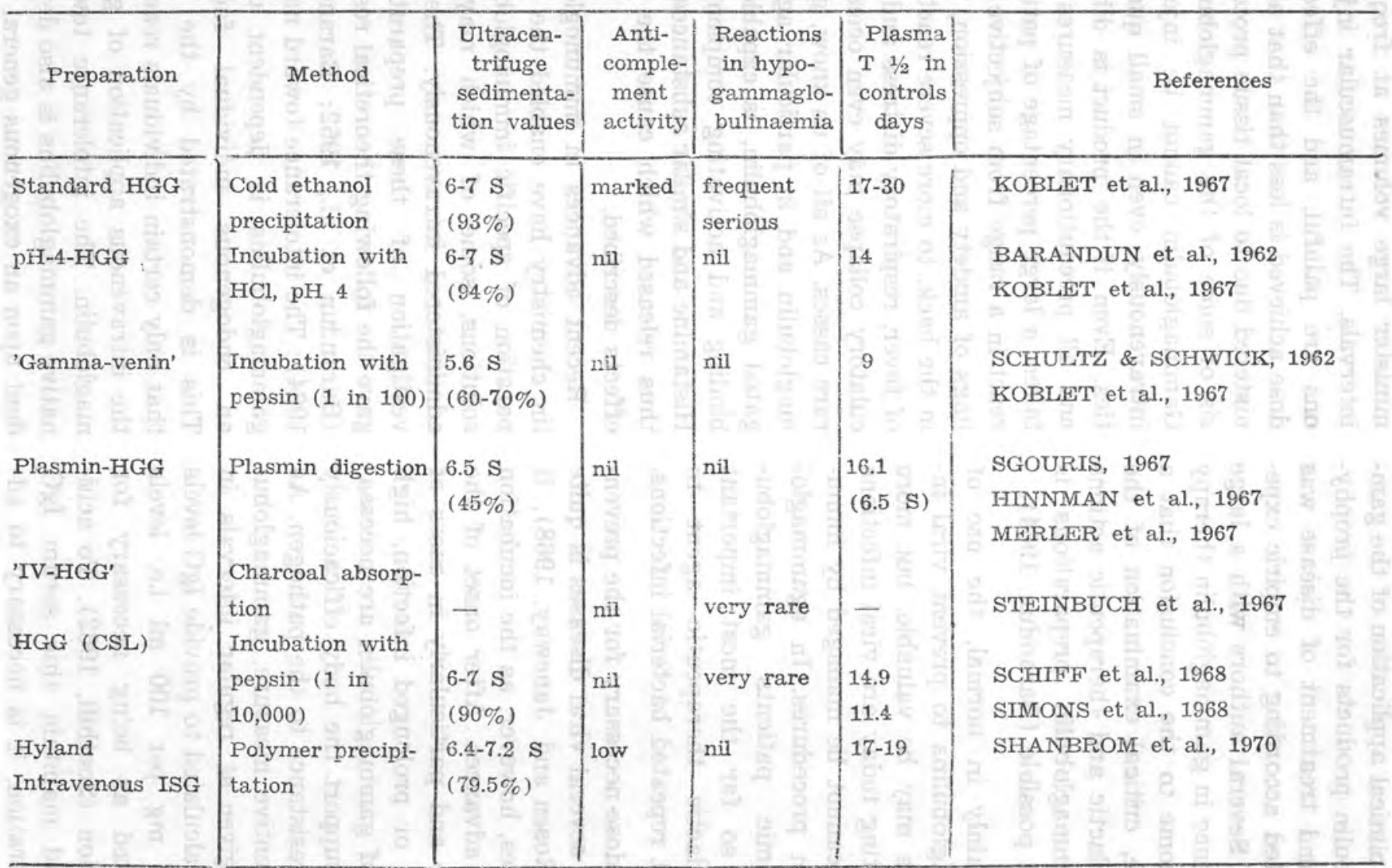

After HAINSKI, M. et al., (1971). 
tor, which is carried by the gammaglobulin ilself. It is connected to its anticomplement activity and tissue binding capacity. Previous attempts to provide an immune serum globulin safe for intravenous use (I.V.G.G.) have utilized Cohn fraction-II derived material. Using acid treatment, enzyme hydrolysis and other procedures, investigators have attacked the Fc portion of the IgG molecule to dissociate the aggregates formed during fractionation and retard their subsequent formation. These aggregaited molecules of IgG have been implicated in previous neponts of vasomotor reactions to I.V.G.G.

The advantages and characteristics of the "ideal" intravenous immune serum globulin:

\section{Advantages}

1. Larger doses are safer and more comfortable.

2. Losses due to locail proteolysis and tissue fixation are reduced.

3. Levell of circulating antibody is immediately increased.

4. Greater efficiency increases probability of succesful treatment at lower cost.

\section{Characteristics}

1. Free of high-molecular weight aggregates.

8. Low in anticomplementary activity.
3. In vivo survival comparable to intramuscular immune serum globuliin.

One of the advantages over the regular intramuscular preparation is the dose to be given. For example, $400 \mathrm{mg} . / \mathrm{Kg}$. of I.V.G.G, has been given in a single infusion. This is equivalent to $2 \frac{1}{2} \mathrm{ml} . / \mathrm{Kg}$. of $16 \%$ intramuscular gammaglobulin, or 50 $\mathrm{ml}$. for a patient weighing $20 \mathrm{Kg}$., an excessively large volume to be given intramuscularly to a child as part of routine management (Simons, 1968). There are different ways to treat standard gammaglobulin to obtain preparations free of anticomplement activity.

Table 1 compares the 7 preparations of I.V.G.G.

The acid treatment seems to work well initially, although it has been noted that the reaction may be incomplete (Schiff et all, 1968). Moreover, the subsequent reaggregation which tends to occur may render the proparation unpredictable chemically as well as clinically. The specific goal of enzyme hydrolysis has been to impair the IgG molecule's ability to aggregate, fix complement, and thus itriger vasomotor reactions. In doing so, however, its clinical efficacy may also have been impaired. Material digested with pepsin has shown markod reduction in its in vivo survival (Janeway et al., 1968; Merler et al., 1967; Wellls et al., 1969). This would 
certainly reduce its prophylactic, if not its therapeutic usefulness. Sgouris and Matz (1967) reported that treatment with plasmin resulted in little or no change in antibody activity (Schiff et al., 1968). Painter (1965) has also reported that in vitro titres of fragmenited material may be deceptive in light of their shortened in vivo survival. Merler et al. (1967) reported situdies on plasmin digested material, and found that $55 \%$ of it was fragmented and rapidly catabolyzed. In the case of Gamma-Venin, the hydrolysis with pepsin and low $\mathrm{pH}$, it seems apparently that the duration of action of Gamma-Venin in the organism is relatively short, because the small fragments cannot be retained (Diggelmann et al., 1964).

Furthermore, a part of the gammaglobulin molecule (fragment Fc, III) is completely destroyed by the treatment mentioned above. This is just the part of the molecule which has no antibody activities, but is carrier of antigenic properties and of groups which bind in a non-specific way to complement and to various tissue structures.

The treatment with pepsin and low $\mathrm{pH}$ results in a gammaglobulin preparation without non-specific properties but leaving intact the an'ibody activities in quantitative and qualitative terms. The commercially I.V.G.G. made by Hyland Division Travenol Laboratories is resuspen- ding the fraction III paste in normal saline and is processed using a polymeric fractionation agent. This is a preparation free of aggregates and low in anticomplementary activity. The in vivo half life was found to be comparable to intramuscular preparations.

The gammaglobulin products which have been available consist allmost exolusively of IgG and cortain mere traces of IgA and IgM. The evaluation of the numerous antibody as. says show that antibodies against antigens are located mainly in the IgG, antibodies against carbohydrate antigens are found in IgM, and certain viral antibodies mainily in IgA. In the course of the immunization process, IgM antibodies appear sooner than IgG, they have more intense agglutinating phage-neutralizing, complement binding, and hemolysing propertiles than IgG (Janeway et all., 1968). It is known that IgA is detected not only in the serum, but also in the secretions of the mucous membranes and in the glands producing external secretions; it occurs in monomeric and polymeryc form. The levell of the IgA fractions in the secretions of the mucous membranes can be higher than that in the serum. All these findings promoted the manufacture of IgA and IgM preparations for clinical applications.

Results obtained by Hobbs (1968) and other investigators (Stiehm and Fudenberg, 1966) have allso proved 
TABLE 2: Types of dysgammaglobulinaemia

\begin{tabular}{c|c|c}
\hline Deficiency & Normal or raised level & Dysgammaglobulinaemia \\
\hline IgA and IgM & IgG & Type I \\
IgG and IgA & IgM & Type II \\
IgG & IgA and IgM & Type III \\
IgA & IgG and IgM & Type IV \\
IgM & IgG and IgA & Type V \\
IgG and IgM & IgA & Type VI \\
\hline
\end{tabular}

After: Hobbs (1968) and Stoelinga (1968).

that besides the classical agammaglobulinemia-Bruton, dysgammaglobulinemic conditions also exist, where not all three, but merely one or two immunoglobulins are decreased or completely lacking.

Table 2 shows the types of dysgammaglobulinaemia detected so far. Antibody deficiency disease of types $\mathrm{I}, \mathrm{V}$ and VI is clinically most important. Patients often suffer from serious bacterial infections (Marder, 1971).

\section{Climical applications}

Besides for both prevention and treatment of infections diseases, of hypo/agammaglobulinemic patients, IgM enriched immunoglobulins were given to 1500 gram underweight newborn and premature infants to prevent them against Gram negative pathogens, particularly Meningococcus, Klebsiella, Pyocyaneus, Coli and Proteus (Cohen and Norins, 1968). Further clinical experiments are beng carried out in the prophylaxis of nfections in pattients treated with cytotoxic agents, and in post-operative prophylaxis of wound infections next ito disturbances of the wound healing process in old people. Besides immunoglobulins, which are obtained from the pooled plasma of healthy dcmors, hyperimmunogilobulin is now produced for the treatment of numerous specific diseases. Tetanus immunoglobulin obtained from vaccinated donors is indicated without precautionary measure as homologous serum both for the prophylaxis and treatment of tetanus. The dosage of human gammagiobulin is considerably lower than that of animal serum, the half life, and thus the duration of effect, is prolonged. Pertussis hyperimmuneglobulin is used for the prevention and treatment of whooping cough, rubella immunoglobulin is used for the prevention of German measles in early pregnancy.

Parotititis immunoglobulin is being used for the prevention of orchitis in young males and adult men. There 
has been repeated corfirmation of the effectiveness of immunoglobulin in preventing infectious hepatitis or at least preventing overt manifestations of liver infection (Krugman, 1963).

Inferential evidence is presented that attenuation of hepatitis-B-antigen (H.B.Ag)-positive hepatitis may favour the progression of acute to chronic liver disease and the development of a persistent H.B.Ag carrier state. These considerations may be relevant to the use of antibody to the hepatitis-B-antigen (anti-H.B.Ag) in the prophyllaxis of hepatitis B. Controlled trials to test the efficacy of anti-H.B.Ag are being planned or are in progress. It is urged that these trials go beyond questions relevant to acute, overt hepatitis and specifically examine the possible in. duction of chronic liver disease and a persistenit viral carrier state (Alter et al., 1972). It is particularly worthy of note that aniti-rhesus serum applied shortly after delivery can prevent morbus hemolyticus necmatorum in the forthcoming sibisings.

\section{Inhibition of humoral immune responses}

The rationale for this procedure is based on experimental finding that the passive administration of antibody to an animal previously chalenged with antigen can suppress the production of endogenous antibody (UHR and Muller, 1968). This prin- ciple has recently been applied in the prevention of $\mathrm{Rh}$ haemolytic disease. The intramuscular injection of a very small volume of high titre anti-Rh (D) antibody is sufficient to suppress the production of red cell damaging antibody. The mechanism of this phenomenon has not been elucidated.

The formation of antigen-antibody complexes are being incriminated in the pathogenesils of an increasing number of disease states. These include diseases as apparently unrelated as acute Glomerulonephritis, serum sickness, systemic Lupus Erythematosus, and renal allograft rejection. With the progressive use of immunoglobulin and antibody solutions the number of these disonderg may even increase. Another area where suppression of immunoglobulin production by specific antiserum may find an application is in the control of IgE dependent reactions that are unresponsive to conventional therarpy. Reaginic antibodies of the IgE class have been shown to be involved in allergic disorders including hay fever, asithma and eczema (Ishizaka et al., 1966). It is conceivable that the infusion of anti IgE antisera may be of therapeutic benefit in intractable cases.

In the preparation of immune antisera which cannot be obtained from human sera and so have to be raised in experimental animals, a major problem is to raise antibodries to a 
restricted range of antigenic determinants. In the production of antilymphocyte serum (ALS) for example, it is well recognised that the injection of human lymphocytes from any of several sources results in the appearance not only of antilymphocyte antibodies but also of antibodies directed against red cells, platelets and other celly types. Elimination of these antibodies from the final preparation is a major practical problem. Absorption procedures are time consuming and pose the difficulty of obtaining red cells and other cells in numbers sufficient for complete $a b$ sorption of the crude ALS (Simons, 1971). Inhibition of haemagglutinins and, other undesired antibodies by the passive administration of antisera at the time of lymphocyte immunisation would be a much more satisfactory alternative.

\section{Limiltations}

The ideal preparation for gammaglobulin therapy would be a gammaglobulin without severe alteration of the molecules, but only slight rearrangements of the intramolecular structure. It could be injected intravenously without risk and would be retained in the organism because of intact molecular size and intact tissue-binding capacity.

Simons et al., (1968) reported that even though the anticomplementary activity of the I.V.G.G. has been raduced by acid pepsin treatment, a number of untoward reactions to infusion of this material were observed. These included pallor, restlessness, tachycardia, drowsiness, headache, nausea and abdominal discomforit. It was found that the occurrance and severity of these side effects were dependent on the rate of infusion, as they appeared whenever the rate exceeded a certain critical value. They were of the opinion that these reactions might be partly due to temporary occlusion of small blood vessels by agglutinated cells, in accordance with their findings that I.V.G.G. agglutinated erythrocytes and leucocytes in vitro. All these findings of limitations indicate that clinically modified gammaglobulin preparations show various degrees of aggregation, reaggregation and fragmentation which make them less than desirable for clinical use.

Complete removal of the Fc fragment and its associated anticomplementary activity can be accomplished only at the expense of splitting off this fragment, with the consequent diminution in tissue binding affinity, and reduction of molecular size. This in turn is accompanied by increasingly rapid elimination in the urine with a reduction of the in vivo half-life to a level cmpracticable for long term therapy. In Simons' serial patients using Gamma-Venin, $80 \%$ of the infused $I^{125}$ labeled material were recovered in the urine during the first 24 hours. 
Another limitation of I.V.G.G. is its use for the routine management of children with immunoglobulin deficiency states which is restricted by the age of the child, since small infants are unlikely to co-operate with monthly intravenous infusions. It may also be inapplicable to those children who require unusually large maintenance doses or who have low threshold for side effects, because the prolonged duration of infusion required would then preclude the practicability of regular therapy on an outpartient basis.

I.V.G.G. is probably less suited than fresh plasma to the emergency treatment of life threatening infecti on in patients known to be agammaglobulinaemic or in whom with a strong suspicion of deficient antibody formation, since it contains negligible amounts of IgA and IgM. Thus in the emergency therapy of agammaglobulinaemic children who have deficiency of all 3 major immunoglobulin classes, it may be preferable to administer fresh plasma (Stiehm et al., 1966) followed by prolonged maintenance of IgG levels by repeated I.V.G.G. infusion. Fresh plasma would be impractical in routine management because of the prolonged infusion periods that would be necessary in order to provide adequate replacement. The price of the gammaglobulin preparations, is also one of the llimitation of its application.

Another limitation especially in developing countries where infecti- ous diseases are still overwhelming, is that the gammaglobulin preparations available are made from healthy donors in affluent countries who never have had infections still existing in the developing countries.

Besides all the limitations mentioned above, there is reason to hope that future improved preparative methods for the modification of gammaglobulin may yet result in a lower anticomplementary activity, a convenientlly long biological half-life, enriched with IgA and IgM, and a reasonable price.

\section{Summary}

An enormous progress in gammaglobulin preparation, which can be administrated intravenously has been described.

Gammaglobulin * therapy is now indicated in: 1. The prevention and treatment of infectious diseases in hypo/agammaglobulinemic patients. 2. IgM enriched immunoglobulins are given to less than 1500 gram under. weight newborns to prevent infection by Gram negative pathogens. 3 . Hyperimmuneglobulin is used for the treatment of numerous infectious diseases. 4. Studies in the use of antibody against hepatitis-B antigen in the prophyllaxis of hepatitis B are in progress. 5, Anti-rhesus serum applied shortly after delivery can prevent morbus hemolyticus neonatorum in forthcoming siblings.

However, limitations to the wide spread use of immunoglobulins still exist. 


\section{REFERENCES}

1. ALTER, H.J., HOLLAND, P.V. SCHMIDT, P.J. and PLOTZ, P.H. : Gamma-globulin for Hepatitis-Virus B. Prevention or extension? Lancet i : 1110 (1972).

2. BARANDUN, S., KISTLER, P., JEUNET, $\mathrm{F}$. and ISLIKER, H. : Intrayenous administration of human gammaglobulin. Vox. Sang. 7 : 157 (1962).

3. BARANDUN, S.: Die Gammaglobulin. Therapie (Karger, Basel/New York 1964).

4. BERRY, C.L.: The neonatal thymus and immune paresis. Proc. R. Soc. Med. 61 : 867 (1968).

5. COHEN, I.R. and NORINS, L.C. : Antibodies of the IgG, IgM and IgA classes in newborn and adult sera reactive with Gram-Negative Bacteria. J. Clin. Invest. $47: 1053$ (1968).

6. DIGGELMANN, H., KOBLET, H. BARANDUN, S. and GERBER, H. : Determination of the total clearance of different preparations of gammaglobulins. Panel meeting on radioisotope techniques in the study of protein metabolism. Vienna 1964.

7. DIGGELMANN, H., KOBLET, H., GERBER, H. and BARANDUN, S. : Bestimmung der totalen Clearance von Standard-Gammaglobulin, pH-4-Gammaglobulin and Gamma-Venin. Path. Microbiol. 27 : 572 (1964).

8. HAINSKI, M., PAYNE, J.H., ORDONEZ, G.A. and SHANBROM, E. : A new preparation of immune serum globulin for intravenous administration.Vox. Sang. $20: 469$ (1971).

9. HOBBS, J.R. : Immune imbalance in Dysgammaglobulinemia Type IV. Lancet i : 110 (1968).
10. ISHIZAKA, K., ISHIZAKA, T. and HORNBROOK, M.M.: Physicochemical properties of reaginic antibody V. Correlation of reaginic activity with gamma-E-globulin antibody. J. Immunol. 97 : 840 (1966).

11. JANEWAY, C.A., MERLER, E. and ROSEN, F.S.: Intravenous gammaglobulin. Metabolism of gammaglobulín fragments in normal and agammaglobulinemic persons. New Engl. J. Med. 278 : 919 (1968)

12. KRUGMAN, S. : The clinical use oî gammaglobulin. New Engl. J. Med. $269: 195$ (1963)

13. MARDER, E.: Immunoglobulin and hyperimmuneglobulin therapy. Ann. Gen, Pract. Submit. 29-35 (1971).

14. MERLER, E., ROSEN, F.S. and SAL MON, S. : Studies with intravenous gammaglobulin. Vox. Sang. 13 : 102 (1967).

15. PAINTER, R.H., WALCROFT, M.J. and WEBER, J.C.W. : The efficacy of fragmented immune serum globulin in passive immunization. Canad. J. Biochem $44: 381$ (1965).

16. ROSEN, F.S. and JANEWAY, C.A. : Diagnosis and treatment of antibody deficiency syndromes. Posgrad. Med 43 : 188 (1968).

17. SCHIFF, P., SUTHERLAND, S.K. and LANE, W.R.: The preparation, testing and properties of human gammaglobulin for intravenous admintstration. Aust. paediatr. J. $4: 121$ (1968).

18. SGOURIS, J.T. and MATZ, M.J. : Observations on the fragmentation of venous and placental immume serum globulin. Vox. Sang. $13: 59$ (1967).

19. SIMONS, M.J., SCHUMACHER, M.J and FOWLER, R.: Intravenous gam. 
maglobulin therapy of immunoglobulin deficiency diseases. Aust. paediatr. J. 4: 127 (1968).

20. SIMONS, M.J. : Trends in immunological therapy. Ann. Gen. Pract. Submit. 36-41 (1971).

21. SOOTHILL, J.F.: The concentration of gammaglobulin and gammamacroglobulin in the serum of patients with hypogammaglobulinaemia. Proc. roy. Soc. Med. 55 : 395 (1962).

22. STIEHM, E.R., VAERMAN, J.P. and FUDENBERG, H.H. : Plasma infusions in immunologic deficiency states: metabolic and therapeutic studies. Blood 28 : 918 (1966).
23. STIEHM, E.R. and FUDENBERG H.H. : Clinical and immunologic features of dysgammaglobulinemia type I. Report of a case diagnosed in the first year of life. Am. J. Med. $40: 805$ (1966).

24. STOElingA, G.B.A. Päd. u. Pädologi 4 : 77 (1968), cited by Marder, E.

25. UHR, J.W. and MULLER, G.: Regulatory effect of antibiody on the immuneresponse. Advances in Immunol. $8: 81$ (1968).

26. WELLS, J.V. and PENNY, R. : Survival studies on a commercial preparation of intravenous human gammaglobulin labelled with I 131. Austr. Ann. Med. 18 : 271 (1969). 